\title{
Provision of community pharmacy services during COVID-19 pandemic: a cross sectional study of community pharmacists' experiences with preventative measures and sources of information
}

\author{
Kreshnik Hoti $^{1}$ (1) $\cdot$ Arianit Jakupi ${ }^{2,3} \cdot$ Dardan Hetemi $^{1} \cdot$ Denis Raka $^{1} \cdot$ Jeffery Hughes $^{4} \cdot$ Shane Desselle $^{5}$
}

Received: 29 April 2020 / Accepted: 2 June 2020 / Published online: 11 June 2020

(c) Springer Nature Switzerland AG 2020

\begin{abstract}
Background An infectious disease caused by a novel coronavirus (later called COVID-19) reached pandemic levels in 2020 and community pharmacists were involved in responding to this pandemic, also in Kosovo. Objectives To explore the experiences of community pharmacists in relation to provision of community pharmacy services during COVID-19 pandemic. Setting Community pharmacists in Kosovo. Methods This was a cross-sectional study where data was collected via a selfadministered online questionnaire, from 264 pharmacists actively practicing in Kosovo during the pandemic. The questionnaire consisted of a combination of closed and open-ended questions, optional statements and statements on a five-point Likert scale, derived at least in part from the Transtheoretical Model. One-way analysis of variance was used to analyze differences in responses to Likert-type items whereas categorical variables were analyzed using Chi square testing. Main outcome measures Community pharmacists' perceptions on COVID-19 related preventative measures. Results A response rate of $40.6 \%$ was achieved. Sufficient and adequate COVID-19-related preventative measures were being implemented by a majority of pharmacies $(n=232 ; 87.9 \%)$, and over two-thirds of respondents agreed/strongly agreed that their pharmacies were sufficiently prepared with protective equipment for their personnel. Implementation of preventative measures was associated with respondents' perception that pharmacists and the pharmacy profession were valued more by patients during the pandemic and to a lesser degree, by other health professionals. Most commonly stated pros dealt with employee and patient safety, while key cons dealt with increased costs and running out of the necessary protective equipment. Key barriers to pharmacy activities were price increases by wholesalers, and patients' panic and excessive buying, whereas drivers dealt with professional obligation to assist and opportunity to prove inseparable to other health professionals. The most popular means of accessing COVID-19 related information by pharmacists was via mobile devices and information from professional organizations was considered most useful by pharmacists. Conclusions Community pharmacies actively implemented various measures as precautions to mitigate the spread of COVID-19. Our findings highlight the value of continuous provision of information by professional organizations and use of mobile devices as key means to access information by pharmacists.
\end{abstract}

Keywords Community pharmacy $\cdot$ Coronavirus $\cdot$ COVID-19 $\cdot$ Information sources $\cdot$ Kosovo $\cdot$ Pharmacist attitudes Pharmacists $\cdot$ SARS-COV2

Kreshnik Hoti

kreshnik.hoti@uni-pr.edu

1 Division of Pharmacy, Faculty of Medicine, University of Prishtina, "Bulevardi i Deshmoreve" Street. NN, 10000 Prishtina, Kosovo

2 Chamber of Pharmacists of Kosova, Prishtina, Kosovo

3 Higher Education Institution, Faculty of Pharmacy, UBT College, Prishtina, Kosovo

4 School of Pharmacy and Biomedical Sciences, Curtin University, Perth, WA, Australia

5 College of Pharmacy, Touro University California, Vallejo, USA

\section{Impacts on practice}

- In addition to their purpose of reducing COVID-19 transmission, sufficient and adequate implementation of preventative measures has a positive effect on patients' and health professional's perception of pharmacists and the pharmacy profession.

- Pharmacy ownership by pharmacists and pharmacists' experience are independently associated with a higher adherence to a number of preventative measures to curb COVID transmission. 
- There are important barriers and drivers to pharmacy services during COVID-19 pandemic and these should be considered by relevant policymakers to ensure better provision of pharmacy services to the community.

- Pharmacists considered COVID-19 related information distributed by professional organizations such as FIP as the most useful and this information was primarily being accessed via mobile devices.

\section{Introduction}

The disease caused by previously unknown severe acute respiratory syndrome coronavirus (SARS-COV2), later named COVID-19, has spread rapidly, with the World Health Organization (WHO) officially declaring it a pandemic on 11th of March 2020 [1, 2]. Various health organizations, institutions and governments worldwide have advocated a number of measures aimed at reducing the spread of the disease and preventing hospitals from being overwhelmed. These measures included hand hygiene techniques, environmental hygiene, social distancing, travel restrictions, border control, quarantine and lockdown measures [1,3-7].

Since the outbreak of COVID-19, pharmacists like other health professionals, have been at the frontline of combating the disease and remained open, therefore playing a significant role in minimizing or avoiding its "community transmission" [8]. Pharmacists are currently involved not only in the provision of medication, COVID-19 prevention products, and medical equipment supplies, but also offering health information related to COVID-19. Considering their ease of access and availability as a first point of contact, pharmacists are involved in early detection, referral and facilitation of implementing various government measures aimed at preventing or slowing down the spread of the disease [4, 9], as well as assisting with raising community awareness, whilst continuing their management of minor conditions with overthe-counter products, promotion of medication adherence and providing home delivery services [10-12]. Experiences from pharmacists in China also reinforce the value of the above services and pharmacists' roles in the context of the COVID-19 outbreak [13].

To assist pharmacists and support personnel in dealing with COVID-19, the International Pharmaceutical Federation (FIP) issued guidelines [15] that provided specifications around preventative measures to reduce infection, preparedness to ensure timely and effective response, immediate actions that pharmacists should take and post-pandemic measures $[11,14]$. Other pharmacy professional bodies around the world have issued recommendations aimed at assisting pharmacists during the pandemic $[15,16]$. Additionally, a number of resources have been made available for pharmacists around the world to assist them with COVID-19 management and clinical decision-making processes $[10$, 15-17].

To date, there is little known about the extent to which community pharmacists are implementing these measures related to COVID-19 globally. This applies to Kosovo, where pharmacists were given the translated version of FIP guidelines and recommendations [14, 16]. These included FIP guidelines on how to counsel patients during COVID-19 [14]. Additional measures from the country's relevant health authorities were also applied to community pharmacies to ensure they remained open, including rent assistance, (i.e. $50 \%$ reimbursement during months of pandemic) and afterhours restrictions where selected pharmacies were rostered to be open between (on 5:00 pm to 6:00 am) [16].

\section{Aim of the Study}

The current study aimed to explore the experiences of community pharmacists in relation to provision of community pharmacy services during COVID-19 pandemic, with a focus on determining the extent of the implementation of COVID-19 preventative measures in community pharmacies, barriers and drivers to their implementation and information resources being used by community pharmacists during the pandemic.

\section{Ethics approval}

Study procedures were approved by the Kosovo Pharmaceutical Chamber and its ethics committee (No. 28/2020).

\section{Methods}

This was a cross-sectional study involving community pharmacists in Kosovo actively practicing during the COVID-19 pandemic. The study used quantitative survey-based methodology to collect the data during April 2020.

\section{Development of data collection instrument}

Data were collected using a self-administered questionnaire. Due to circumstances created with the outbreak of COVID19 in the country, the questionnaire was made available for online administration to community pharmacists. Questionnaire development considered previous literature reporting collection of pharmacists' experiences and opinions in the area of pharmacy practice [18-20]. This literature informed the questionnaire in relation to design issues and types of questions and statements. Some of the questionnaire's content was inspired by the Transtheoretical Model (TTM), a useful approach to 
predict community pharmacists' potential behavioral changes [21]. In this case, the study evaluated putative "pros" and "cons" for implementation of COVID-19 safeguards, as these can help govern any educational intervention in the future aimed to describe their decisional balance in potentially changing practice behavior. [21] Also considered was recent literature, COVID-19 related information and guidelines provided to pharmacists and community pharmacy staff locally and internationally by FIP, Pharmacy Guild of Australia, Kosovo Pharmacists' Chamber (KPC), National Institute of Public Health and the Ministry of Health [16]. In order to test the content and face validity of the questionnaire, the first draft of the questionnaire was initially piloted amongst seven practising pharmacists, following which a number of modifications were made; for example, an item was added regarding the effects of the pandemic on community pharmacy finances, potentially necessitating staff reduction. Information was extracted using a variety of question/statement types: closed-ended (i.e. Yes/ No) questions, open-ended questions, optional statements and statements on a five-point, Likert-type scale.

Initially, community pharmacists were asked to complete the questionnaires via their KPC social media account. A mobile message containing the link to the online questionnaire was also sent to all KPC members list, which includes all pharmacists in Kosovo, specifically asking community pharmacists to follow the link and respond. This message was sent by the KPC. A reminder was sent by the KPC to community pharmacists who did not respond after 4 days. The questionnaire was also distributed to a closed social media group, identified by researchers, consisting of Kosovo community pharmacists. Community pharmacists self-administered the questionnaires from 1st to 12th of April 2020.

\section{Data analysis}

SPSS V. 26.0 was used to analyze the data. Groups of statements related to (a) preventative measures in pharmacy, (b) barriers to activities and (c) drivers to activities in the pharmacy during COVID-19 where checked for internal consistency using Cronbach's alpha coefficient. Demographic characteristics and responses to various questions/statements were initially analyzed using descriptive statistics. Comparisons across demographic characteristics were made using Chi square statistics. Differences in responses to Likert-type items were discerned using one-way analysis of variance (ANOVA). For both types of analysis, conditions of testing were met i.e.: assumptions of normality and homogeneity of variance for one-way ANOVA and random sampling, categorical variable and no cells with expected count of less than 5 for Pearson's Chi squared testing.

\section{Results}

A total of 264 community pharmacists self-administered the online questionnaire, yielding a response rate of approximately $40.6 \%$, based on an estimated total number of 650 actively practising community pharmacists in Kosovo. Respondents were working in pharmacies dispersed among 27 different localities, which included all of Kosovo's major regions, cities and towns. Additional details on respondent demographics are provided in Table 1.

\section{Barriers and drivers to activities in the pharmacy during COVID-19 pandemics}

Most pharmacists $(\mathrm{n}=191,72.3 \%)$ indicated that they had continuously received requests from patients to supply (without prescription) medications currently being discussed for COVID-19 treatment. Pharmacists were actively involved in counselling and educating patients in regard to these treatments $(n=242,91.7 \%)$ and were also serving patients for other non-COVID-19 related conditions $(n=249,94.3 \%)$. Additionally, most pharmacists indicated that there has been a significant reduction in patients visiting pharmacy for conditions not related to COVID-19 and that their pharmacy had been significantly impacted financially as a result $(n=181$, $68.6 \%$, and $n=160,60.6 \%$, respectively). Approximately one-third of respondents also indicated that reduction in staffing in their pharmacy would be needed due to the negative impact of COVID-19 on the business ( $\mathrm{n}=89,33.8 \%)$.

Key barriers to activities in the pharmacy during the pandemics were: price increases imposed by pharmaceutical wholesalers $(n=208,78.8 \%)$, patients' pandemics related panic $(n=202,76.5 \%)$ and their unnecessary and excessive

Table 1 Demographic characteristics of community pharmacists practicing during the COVID-19 outbreak

\begin{tabular}{llc}
\hline Characteristic & Description & $\mathrm{n}(\%)$ \\
\hline Gender & Female & $178(67.4)$ \\
& Male & $86(32.6)$ \\
Community pharmacy & $<1$ year & $25(9.5)$ \\
experience & 2-5 years & $79(29.9)$ \\
& 6-10 years & $57(21.6)$ \\
& $>10$ years & $103(39)$ \\
Pharmacy ownership & Owner & $110(41.7)$ \\
& Another pharmacist owner & $72(27.3)$ \\
& Owner not a pharmacist & $82(31.1)$ \\
Number of pharmacy staff & 1 & $64(24.2)$ \\
working on the same shift & $2-3$ & $151(57.2)$ \\
& 4 & $26(9.8)$ \\
& $>5$ & $23(8.7)$ \\
\hline
\end{tabular}


buying of products $(\mathrm{n}=190,72.0 \%]$. Key drivers included: the moral and professional obligation to offer pharmaceutical assistance ( $\mathrm{n}=227,86 \%)$ and the opportunity to prove pharmacists as being an inseparable part of health professionals $(n=218,82.6 \%)$. More information on the pharmacists' responses is provided in Table 2. Internal consistency, using Cronbach's alpha, for the above statements related to barriers and drivers to activities in the pharmacy during pandemics was 0.621 and 0.726 respectively.

\section{Pharmacists COVID-19 related resources and information sources}

The vast majority of respondents indicated that resources and information provided by pharmacy professional bodies such as FIP and KPC during the pandemic were of considerable help to their practice $(n=238,90.2 \%)$. Just over half of respondents indicated they needed further COVID-19 related training and education to better deal with the pandemic situation $(n=149,56.4 \%)$. Figure 1

Table 2 Barriers and drivers towards activities in the pharmacy during COVID-19 pandemics

\begin{tabular}{|c|c|c|c|}
\hline Barriers & $\mathrm{n}(\%)$ & Drivers & $\mathrm{n}(\%)$ \\
\hline Price increase from pharmaceutical wholesalers & $208(78.8)$ & $\begin{array}{l}\text { Moral and professional obligation of offering pharmaceuti- } \\
\text { cal assistance }\end{array}$ & $227(86)$ \\
\hline Patients' pandemics related panic & $202(76.5)$ & $\begin{array}{l}\text { Opportunity to prove yourselves as being an inseparable } \\
\text { part of health professionals }\end{array}$ & $218(82.6)$ \\
\hline Patients buying unnecessary and excessive products & $190(72)$ & Professional satisfaction with help offered to patients & $185(70.1)$ \\
\hline Worrying about getting infected yourself with COVID-19 & $150(56.8)$ & Opportunity to elevate your personal professional image & $181(68.6)$ \\
\hline Frequent pharmacy inspections by authorities & $130(49.2)$ & $\begin{array}{l}\text { Professional satisfaction with your contribution to prevent- } \\
\text { ing COVID-19 }\end{array}$ & $162(61.4)$ \\
\hline Inadequate financial compensation during pandemics & $103(39)$ & $\begin{array}{l}\text { Better opportunity to use your pharmaceutical skills and } \\
\text { knowledge }\end{array}$ & $157(59.5)$ \\
\hline Increased influx of patient in the pharmacy & $93(35.2)$ & $\begin{array}{l}\text { Opportunity to elevate the image of the pharmacy you } \\
\text { work at }\end{array}$ & $140(53)$ \\
\hline $\begin{array}{l}\text { Misinformation around COVID-19 potential treatment } \\
\text { options }\end{array}$ & $68(25.8)$ & Measures taken by relevant health institutions & $84(31.8)$ \\
\hline Lack of your adequate information on COVID-19 & $54(20.5)$ & $\begin{array}{l}\text { Being in line with competition from other pharmacies in } \\
\text { the market }\end{array}$ & $41(15.5)$ \\
\hline Lack of protective equipment in your pharmacy & $53(20.1)$ & Financial reimbursement you receive during this period & $23(8.7)$ \\
\hline Price increase of pharmaceutical products in the pharmacy & $52(19.7)$ & & \\
\hline Pharmacy's extended working hours & $43(16.3)$ & & \\
\hline Lack of staff in the pharmacy & $31(11.7)$ & & \\
\hline Lack of time & $37(14)$ & & \\
\hline
\end{tabular}
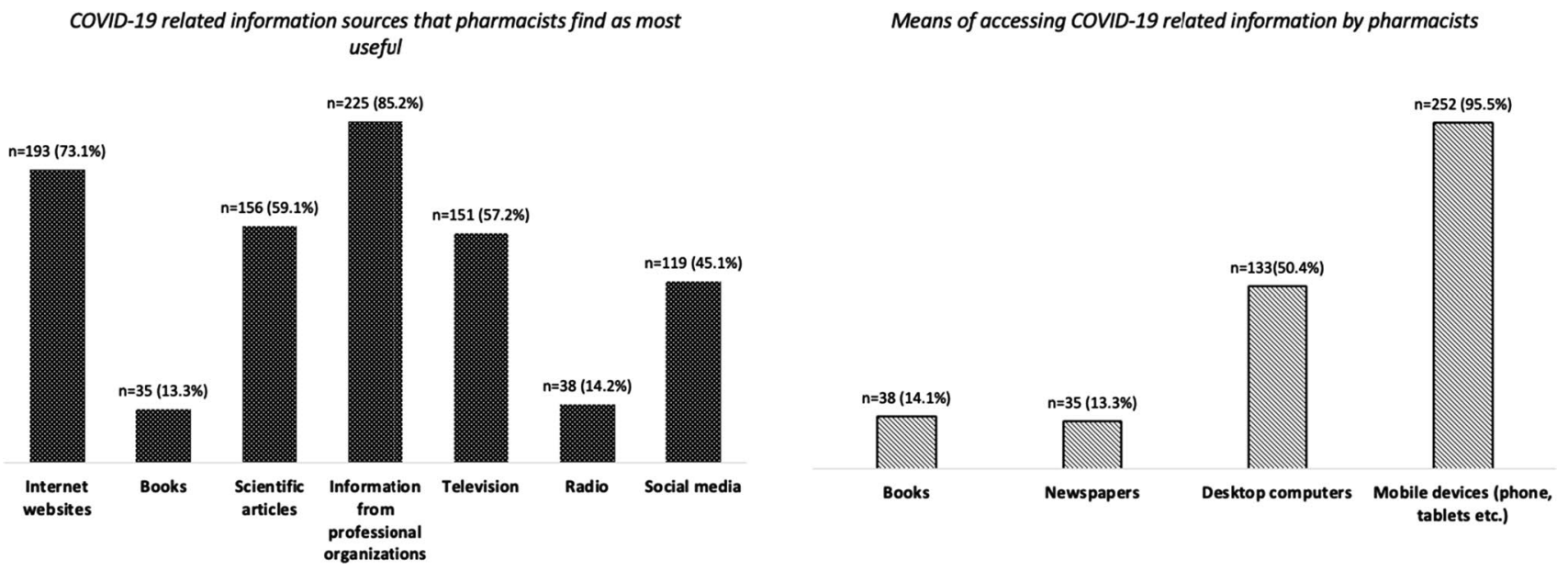

Fig. 1 Pharmacists' information sources and means of access during COVID-19 pandemics 
outlines which information resources were being used by pharmacists and how these resources were being accessed. Information from pharmacy peak professional bodies was suggested to be the most useful source of information for pharmacists during COVID-19 $(n=225,85.2 \%)$. Access via mobile devices was the most popular means of accessing information $(n=252,95.5 \%)$.

Findings from descriptive statistics indicated that in most pharmacies, sufficient and adequate measures were taken to minimize coronavirus transmission to their patients $(\mathrm{n}=232 ; 87.9 \%)$. Chi square testing indicated that pharmacists who were also owners $[\mathrm{n}=109(99.1 \%)]$ were more likely $(p<0.001)$ to respond affirmatively to this question, compared to pharmacists working in pharmacies with another pharmacist owner $[\mathrm{n}=57(79.2 \%)]$; or those pharmacists working in a pharmacy with a non-pharmacist owner $[\mathrm{n}=66(80.5 \%)]$. Similarly, this was the case for pharmacies who had a pharmacist $[\mathrm{n}=166(91.2 \%)]$ in comparison to non-pharmacist ownership [ $\mathrm{n}=66(80.5 \%), p=0.014]$. Over $80 \%$ of respondents agreed or strongly agreed that they were professionally ready in terms of knowledge to deal with COVID-19 in the pharmacy. In this regard, no significant differences were observed between pharmacists depending on their experience, pharmacy ownership status, or number of pharmacy staff.
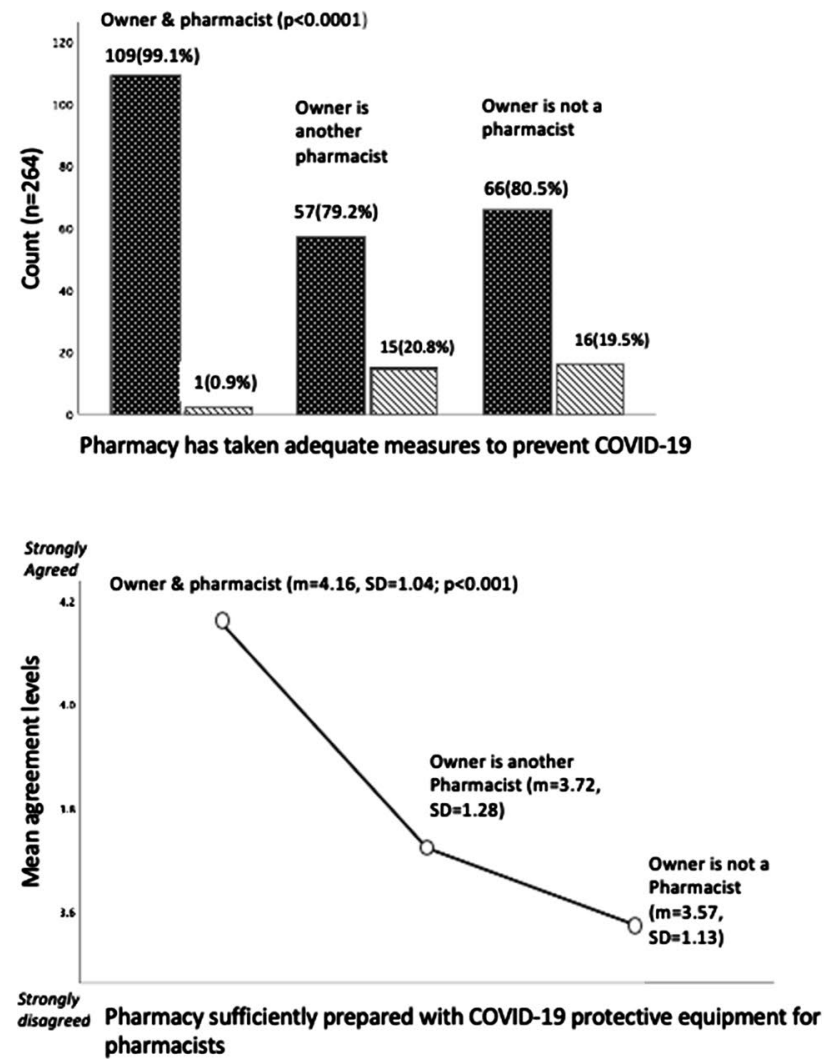

Over two-thirds [n=179 (67.8\%] of respondents agreed or strongly agreed that the pharmacy where they work was sufficiently prepared with protective equipment for pharmacists to deal with the COVID-19 outbreak in the pharmacy. As illustrated in Fig. 2, one-way ANOVA and Tukey's post hoc comparison suggested that pharmacists who were owners $(m=4.16, S D=1.04)$, compared to pharmacists working in pharmacies with another pharmacist owner $(\mathrm{m}=3.72$, $\mathrm{SD}=1.28$ ) or those pharmacists working in a pharmacy with a non-pharmacist owner $(\mathrm{m}=3.57, \mathrm{SD}=1.13)$ were more likely to agree with this statement $(p=0.001)$. Respondents working in pharmacies with pharmacist ownership $(\mathrm{m}=3.99, \mathrm{SD}=1.18)$ were also more likely to agree with this statement $(p=0.007)$, compared to pharmacists working in pharmacies with non-pharmacist ownership $(\mathrm{m}=3.57$, $\mathrm{SD}=1.13$ ).

Additionally, compared to pharmacists with less experience, pharmacists who had more experience working in the pharmacy ( $>5$ years), also agreed more with that the pharmacy where they work was sufficiently prepared with protective equipment for pharmacists to deal with the COVID-19 outbreak in the pharmacy $[\mathrm{m}=4.03, \mathrm{SD}=1.12 ; p=0.004)$.
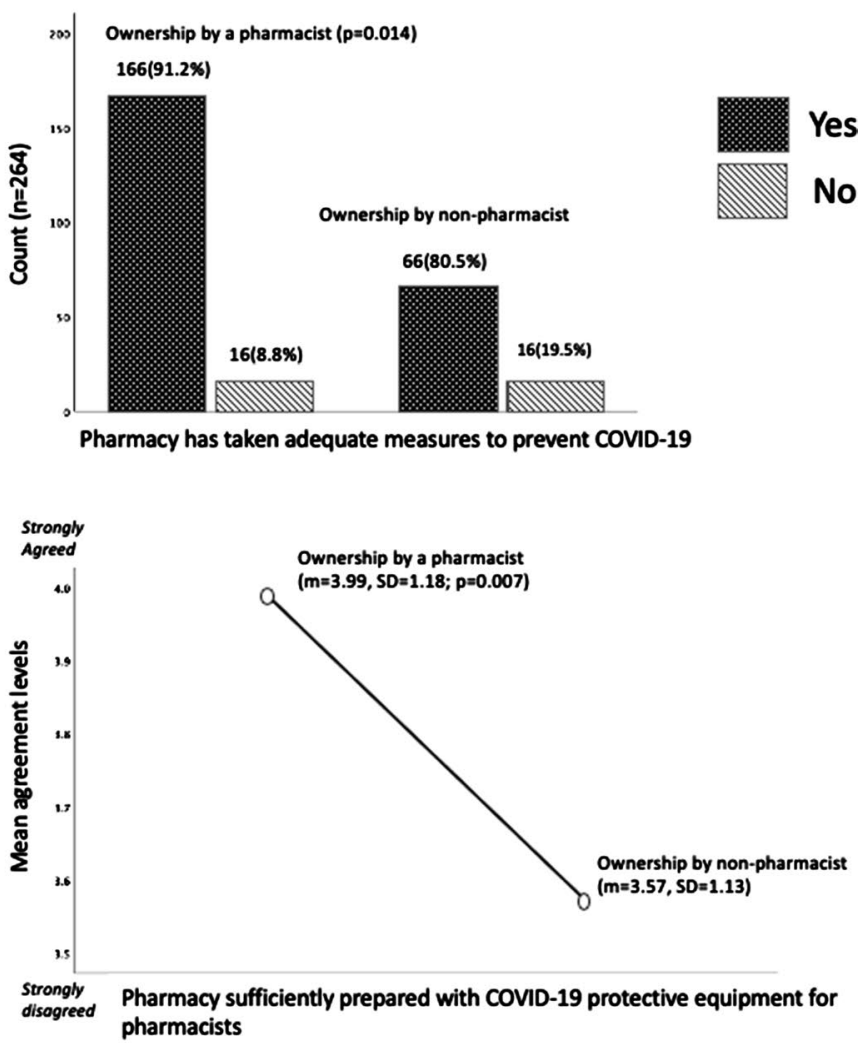

Fig. 2 Association between ownership and pharmacy's preparedness for COVID-19 


\section{Protective equipment used by pharmacists}

The vast majority of pharmacists used protective gloves and hand disinfectants followed by surgical masks $(\mathrm{n}=257,97 \% ; \mathrm{n}=254,96.2 \%$, and $\mathrm{n}=214(81.1 \%)$, respectively] during their practice. Personal protective equipment (PPE) and N95 masks were used less frequently ( $n=130,49.2 \%$ and $n=66,25 \%$, respectively). In relation to the above, Chi square testing against gender, pharmacy ownership, pharmacy experience and number of pharmacy staff identified the following significant differences. Female pharmacists used N95 masks and PPE less frequently $[\mathrm{n}=142(79.8 \%), p=0.017$ and $\mathrm{n}=99(55.6 \%)$, $p=0.023$, respectively]. In comparison to pharmacists with 6 or more years of experience, PPE was used less by pharmacists with 5 years or less of experience in pharmacy [ $\mathrm{n}=65(61.3 \%), p=0.005]$. No other statistically significant difference was observed related to pharmacists' experience and protective measures used. Respondents from pharmacies with pharmacist owners were more likely to use N95 masks $[\mathrm{n}=52(28.6 \%), p=0.026]$ and less likely to use surgical masks [ $\mathrm{n}=42(23.1 \%), p=0.011]$. The number of pharmacy staff was not statistically related to any of the above.

\section{Preventative measures and recommendations in the pharmacy}

Frequency distributions of preventative measures and recommendations that were being applied in respondents' community pharmacies are described in Table 3. Internal consistency, using Cronbach's alpha, of statements related to these measures was 0.764 . Chi squared testing identified significant differences related to pharmacists' experience working in the pharmacy and preventative measures being applied. In this regard, pharmacists who had over

Table 3 A summary of preventative measures being applied by community pharmacies during COVID-19 outbreak

\begin{tabular}{|c|c|c|c|}
\hline Preventive measure & $\mathrm{n}(\%)$ & Experience ( $>5$ years); $\mathrm{n}(\%)$ & Pharmacist ownership; $\mathrm{n}(\%)$ \\
\hline The pharmacy is cleaned and disinfected every day regularly & $203(76.9)$ & $p=0.005 ; 131(82.9)$ & \\
\hline $\begin{array}{l}\text { Pharmacy staff has been notified and educated about COVID-19 pre- } \\
\text { ventative measures }\end{array}$ & $200(75.8)$ & & $p=0.027 ; 145(79.7)$ \\
\hline $\begin{array}{l}\text { Staff changes coats more frequently compared to pre-COVID-19 } \\
\text { period }\end{array}$ & $196(74.2)$ & $p=0.001 ; 129(81.6)$ & \\
\hline $\begin{array}{l}\text { Contact with patients is avoided. Staff does not interact with patients } \\
\text { without personal protective equipment }\end{array}$ & $195(73.9)$ & & \\
\hline $\begin{array}{l}\text { Staff avoids and minimizes wearing accessories such as bracelets, } \\
\text { watch, rings }\end{array}$ & $186(70.5)$ & & \\
\hline Distance between pharmacy staff and patients is 2 meters & $177(67)$ & $p=0.031 ; 144(72.2)$ & \\
\hline No more than one patient is allowed in the pharmacy at the same time & $161(61)$ & $p=0.049 ; 104(65.8)$ & \\
\hline $\begin{array}{l}\text { The counter is cleaned or disinfected after encounter with each client } \\
\text { and hands are disinfected with an alcohol-based product }\end{array}$ & $160(60.6)$ & & \\
\hline $\begin{array}{l}\text { Persons who are not pharmacy staff (including drug distributors) are } \\
\text { not allowed to enter inside areas of the pharmacy }\end{array}$ & $144(54.5)$ & $p=0.049 ; 94(59.5)$ & $p=0.039 ; 107(58.8)$ \\
\hline $\begin{array}{l}\text { The pharmacy is disinfected following a visit from a suspected } \\
\text { COVID-19 patient }\end{array}$ & $116(43.9)$ & & $p=0.003 ; 91(50)$ \\
\hline $\begin{array}{l}\text { Patients are provided with hand disinfectants before entering the } \\
\text { pharmacy }\end{array}$ & $109(39.8)$ & & $\mathrm{p}=0.019 ; 81(44.5)$ \\
\hline $\begin{array}{l}\text { A protective window is placed at the OTC counter (if it did not exist } \\
\text { before) }\end{array}$ & $104(39.4)$ & & \\
\hline $\begin{array}{l}\text { Adequate signage has been prepared and placed at pharmacy entrance } \\
\text { assisting patients to self-identify in case they are at risk of COVID- } \\
\text { 19, therefore alerting the staff immediately }\end{array}$ & $103(39)$ & $p=0.036 ; 71(44.9)$ & $p=0.004 ; 83(45.6)$ \\
\hline $\begin{array}{l}\text { There is only one person per counter or OTC desk and only essential } \\
\text { items are kept at the counter }\end{array}$ & $81(30.7)$ & & \\
\hline $\begin{array}{l}\text { Placing a service counter at the front of the pharmacy so that patients } \\
\text { do not enter pharmacy premises }\end{array}$ & $63(23.9)$ & & \\
\hline $\begin{array}{l}\text { The pharmacy has and applies procedures when identifying a patient } \\
\text { with suspected COVID-19 }\end{array}$ & $61(23.1)$ & & $p=0.012 ; 50(27.5)$ \\
\hline $\begin{array}{l}\text { The pharmacy has a specific area for isolating patients suspected with } \\
\text { COVID-19 }\end{array}$ & $10(3.8)$ & & \\
\hline No additional measures taken, same as before COVID-19 pandemic & $7(2.7)$ & & \\
\hline
\end{tabular}


5 years of experience were more likely to apply a number of preventative measures, compared to pharmacists with 5 or less experience. Also, respondents working in pharmacies with pharmacist ownership were more likely to apply certain preventative measures. These differences have also been provided in Table 3. It is worth noting that, majority of pharmacists [223 (84.5\%)] indicated that additional preventative measures would be implemented in their pharmacy in the near future.

\section{Reasons for and against implementing protective and preventative measures in pharmacy}

Staff safety $(\mathrm{n}=256,97 \%)$ followed by patient safety $(\mathrm{n}=245(92.8 \%)$, prevention of COVID-19 transmission $(n=245,92.8 \%)$ and implementation of government measures $(n=238,90.2 \%)$ were the key reasons for applying COVID-19 protective and preventative measures in the pharmacy. On the other hand, most pharmacists did not agree with potential proffered reasons for not applying COVID-19 protective and preventative measures in the pharmacy (see Table 4).

Over $60 \%$ of pharmacists agreed or strongly agreed with pharmacy-specific measures from relevant institutions/ organizations. Pharmacists suggested that the following measures from authorities had the most positive effect on fighting COVID-19 in their pharmacy: protective measures in the pharmacy $(n=226,85.6 \%)$, recommendations on how to counsel patients $(n=203,76.9 \%)$, restrictions on citizens' movements $(n=189,71.6 \%)$, and restrictions around pharmacy working hours $(n=170,64.4 \%)$. Most pharmacists did not agree that government decisions around rent reimbursement $(n=181,68.6 \%)$, and after-hours pharmacies $(n=158$,
59.8\%) had a positive effect on combating COVID-19 in their pharmacy.

Just over half of the pharmacists agreed or strongly agreed that their work as pharmacists and the profession of pharmacy in general was creating a greater sense of value for pharmacists among patients, but only $40.9 \%$ said the same regarding perceived value of pharmacists by other healthcare professionals. One-way ANOVA results suggested that pharmacists working in pharmacies that have taken sufficient measures to prevent COVID-19 were more likely to perceive value creation by patients and by other health professionals during the pandemic $(\mathrm{m}=3.58, \mathrm{SD}=1.25, p<0.0001$ and $\mathrm{m}=3.31, \mathrm{SD}=1.26, p=0.009$, respectively).

\section{Discussion}

To the authors' best knowledge this is the first study quantitatively reporting on the extent of preventative measures taken by community pharmacists during the COVID-19 pandemic. The majority of community pharmacies had implemented preventative measures and use of protective equipment in their pharmacies. These findings corroborate previous studies reporting the critical role that pharmacists can play in combating COVID-19 [4, 10, 11]. In fact, the current study suggests that pharmacists working in pharmacies that have taken adequate measures against COVID-19 believe that they have created additional value for their patients and to some extent for other health professionals as well. Respondents who were also pharmacy owners and those working in pharmacies owned by a pharmacist (in comparison to a non-pharmacist), seemed to have a stronger association with the above. Pharmacy ownership differences on pharmacists' roles have been reported before

Table 4 Reasons in favor of and against applying protective measures in the pharmacy

\begin{tabular}{|c|c|c|c|}
\hline Reasons in favor (pros) & $\mathrm{n}(\%)$ & Reasons against (cons) & $\mathrm{n}(\%)$ \\
\hline Staff safety & $256(97)$ & None of the above & $102(38.6)$ \\
\hline Patient safety & $245(92.8)$ & High cost of applying measures & $74(28)$ \\
\hline Prevention of COVID-19 & $245(92.8)$ & Running out of necessary supplies & 57 (21.6) \\
\hline Implementing law and recommendations by authorities & $238(90.2)$ & $\begin{array}{l}\text { You want to become an example that things should be taken } \\
\text { without stress }\end{array}$ & $51(19.3)$ \\
\hline In general, it's the right thing to do & $140(53)$ & Loss of income & $47(17.8)$ \\
\hline Ensuring your business for the future, after COVID-19 & $135(51.1)$ & $\begin{array}{l}\text { Challenge of returning to usual business if pharmacy's daily } \\
\text { operations are changed substantially }\end{array}$ & $51(15.5)$ \\
\hline Maintaining the integrity of pharmacy supplies & $134(50.8)$ & You think that COVID-19 will not last long & $37(14)$ \\
\hline Becoming an example for other pharmacies & $115(43.6)$ & You think that COVID-19 is not that contagious & $9(3.4)$ \\
\hline $\begin{array}{l}\text { If not applying measures, there is concern from compe- } \\
\text { tition and losing business to other pharmacies }\end{array}$ & $25(9.5)$ & $\begin{array}{l}\text { Other pharmacies around you are not applying measures and } \\
\text { you don't want to be the only pharmacy around applying } \\
\text { measures }\end{array}$ & $9(3.4)$ \\
\hline \multirow[t]{2}{*}{ None of the above } & $1(0.4)$ & You think that COVID-19 is not that severe & $21(8)$ \\
\hline & & In general, it's not the right thing to do & $5(1.9)$ \\
\hline
\end{tabular}


[22]. Ownership differences identified in the current study should be considered by policymakers in relation to potential implications for implementing future public health-related initiatives and services in community pharmacies.

Our findings also suggest that COVID-19 related information provided by professional organizations, such FIP and local KPC, was perceived to be the most useful during the pandemic. In this regard, it should be emphasized that the KPC also distributed to Kosovo pharmacists and translated FIP resources and recommendations. Additionally, we identified a significant reliance on the use of mobile devices, as means of accessing COVID-19 related information by pharmacists, compared to other methods such as books, newspapers and desktop computers. This emphasizes the big shift to mobile device technology use in pharmacy practice and could also potentially inform organizations and information providers on reviewing the need to customize distributed information for access via mobile devices (e.g. via apps).

The findings indicate that measures recommended by FIP and those recommended by Zheng et al. based on pharmacists' experiences in China, were being implemented in Kosovo community pharmacies $[13,14]$. However, the study identified a degree of variability in terms of uptake and types of preventative measures applied. For example, measures related to avoiding patient contact, social distancing, limitation of patient numbers in the pharmacy and measures related to hygiene, cleaning and disinfection (of pharmacy and staff) were being implemented by majority of pharmacies. However, having a specific area for isolating patients suspected with COVID-19 was taken up far less frequently. Previous studies have reported that pharmacists considered this measure may put pharmacy staff at risk of infection by attracting individuals to come to the pharmacy, considering it a safe place in this regard [10]. Furthermore, this measure was also reported impractical to implement due to cost and time-consumption for community pharmacies [23]. In Kosovo, most community pharmacies are not designed in a way that would easily enable dedication of a separate area for patient isolation, therefore making the above arguments even more relevant. Based on these findings, alternative arrangements such as closer collaboration and specific arrangements with nearby medical clinics and facilitated referral pathways should be considered for pharmacies with similar infrastructural challenges. Our study also identified that adherence to certain preventative measures is related pharmacists' experience ( $>5$ years) and whether the pharmacy is owned by a pharmacist or not. These differences point towards modifiable interventions that could be considered by policymakers in lieu of efforts to improve the response of the profession to a pandemic situation. For example, according to our findings, in pharmacies owned by non-pharmacists, more emphasis may be needed on notifying and educating pharmacy staff on COVID-19 related preventative measures.
Findings also suggest that pharmacists' experience is independently associated with a higher adherence to certain preventative measures. Additionally, adherence to some of the preventative measures such as 'disinfection following a visit from a suspected COVID-19 patient', may be affected by the fact that some pharmacists may have lacked direct exposure to COVID-19 cases prior to and during the time of data collection.

Pharmacists considered that key barriers to pharmacy activities during COVID-19 were price increases imposed by pharmaceutical wholesalers and patients' COVID-19 related panic and their unnecessary and excessive buying of products. An 'unprecedented demand' for over-the-counter drugs and increased drug prices by suppliers have been reported elsewhere $[24,25]$. Due to drug shortages, increases in the cost of paracetamol in the range of five to ten fold was found in the UK, dependent on suppliers, prompting monitoring by authorities [25]. Similar monitoring has also taken place in our respondents' pharmacies and in fact nearly half of them considered frequent inspections by authorities to be barriers towards activities in the pharmacy during the pandemic. Useful to alleviate issues around patients' high and unnecessary demand of pharmacy products could be recommendations from Carico et al., who suggest that pharmacists could motivate patients behavioral change through using a health belief model [26]. This could particularly assist pharmacists' education of patients with limited health literacy and especially those who otherwise do not need additional pharmacy supplies or those asking for medications that are not proven or are prescription only.

Following pharmacists moral and professional obligation to provide services during COVID-19, the greatest driver to activities in the pharmacy was the opportunity for pharmacists to prove themselves an inseparable part of health professionals. Additionally, our study suggests that pharmacists working in pharmacies that have taken adequate measures to prevent COVID-19, were valued more professionally by patients and other health professionals during the pandemic.

\section{Study limitations}

The response rate has been calculated from the total number of pharmacists working in Kosovo's 650 community pharmacies. This is an approximate estimated number of pharmacists provided by the KPC based on a number of factors in Kosovo. Potential selection bias of community pharmacists is expected to be minimal considering that the KPC contacted pharmacists in all pharmacies of Kosovo. However, a higher response rate would be desirable to account for nonrespondents who potentially do not share the same views. Another potential limitation could be the applicability of the findings in the context of other countries where pharmacists practice according to different regulative specifications. The 
focus of this study however was on issues which are new to pharmacists in Kosovo, just like they are new to pharmacists elsewhere, and most of the measures reported here are universally recommended by the FIP [14].

Finally, it is worth emphasizing that this study was conducted during a very challenging period of time when the pandemic in Kosovo was escalating quickly. Therefore, as COVID-19 and causalities in the country progress, new circumstances may affect pharmacists' opinions and as suggested by the majority of our respondents, additional preventative measures might need to be taken by community pharmacies. In this regard, it should be also considered that as the pandemic situation evolves, and the burden on hospitals increases, as suggested by the situation in Italy where some hospitals reported up to $80 \%$ of their beds being occupied by COVID-19 patients, reliance on services offered by community pharmacists may also increase [26, 27].

\section{Conclusion}

Community pharmacists were actively involved in implementation of activities and measures aimed at preventing COVID-19 transmission. This provides further evidence of their crucial role in the health system's response to the management of the pandemic. This study reports adherence to key preventative measures and activities implemented by community pharmacists in Kosovo, including the extent of their implementation, the pros and cons for and against their implementation, and the barriers and facilitators to such measures. Greater implementation of preventative measures by pharmacies was associated with perceptions that pharmacists and the pharmacy profession were valued more by patients and to some extent by other health professionals. Information distributed by professional organizations such as FIP, was identified to be most useful by pharmacists in dealing with COVID-19 and this information was mainly accessed via mobile devices.

Acknowledgements Authors wish to acknowledge all pharmacists in Kosovo who participated in this research.

Funding No special funding was obtained for this research.

Conflicts of interest Authors declare no conflict of interests.

\section{References}

1. World Health Organization Department of Communications. Novel Coronavirus (2019-nCoV): strategic Preparedness and Response Plan. 2019; https://www.who.int/docs/default-source/ coronaviruse/srp-04022020.pdf. Accessed 05 April 2020.

2. World Health Organization. WHO Director-General's opening remarks at the media briefing on COVID-19-11 March 2020. https://www.who.int/dg/speeches/detail/who-director-general-sopening-remarks-at-the-media-briefing-on-covid-19-11-March -2020. Accessed 10 April 2020.

3. Centers for Disease Control and Prevention. Implementation of mitigation strategies for communities with local COVID-19 transmission. https://www.cdc.gov/coronavirus/2019-ncov/downloads/ community-mitigation-strategy.pdf. Accessed 05 April 2020.

4. Ung CO. Community pharmacist in public health emergencies: Quick to action against the coronavirus 2019-nCoV outbreak. Res Soc Admin Pharm. 2020;16(4):583-6.

5. Lau H, Khosrawipour V, Kocbach P, Mikolajczyk A, Schubert J, Bania J, Khosrawipour T. The positive impact of lockdown in Wuhan on containing the COVID-19 outbreak in China. J Travel Med. 2020; 27(3):taaa037.

6. Paterlini M. On the front lines of coronavirus: the Italian response to Covid-19. BMJ. 2020; 368:m1065.

7. The Lancet Respiratory Medicine. COVID-19: delay, mitigate, and communicate. Lancet Resp Med. 2020; S2213-2600(20) 30128-4.

8. Amariles P, Ledezma-Morales M, Salazar-Ospina A, HincapiéGarcía JA. How to link patients with suspicious COVID-19 to health system from the community pharmacies? A route proposal. Res Social Adm Pharm. 2020 (in press).

9. Todd A, Copeland A, Husband A, Kasim A, Bambra C. The positive pharmacy care law: an area-level analysis of the relationship between community pharmacy distribution, urbanity and social deprivation in England. BMJ Open. 2014;4(8):e005764.

10. Al-Quteimat OM, Amer AM. SARS-CoV-2 outbreak: How can pharmacists help? Res Social Adm Pharm. 2020 (in press).

11. Cadogan CA, Hughes CM. On the frontline against COVID-19: community pharmacists' contribution during a public health crisis. Res Social Adm Pharm. (in press).

12. The Pharmaceutical Society of Australia. Coronavirus disease (COVID-19) information for pharmacists. https://www.psa.org. $\mathrm{au} /$ coronavirus/\#Information-on-programs-and-regulatory-issue s. Accessed 21 April 2020.

13. Zheng SQ, Yang L, Zhou PX, Li HB, Liu F, Zhao RS. Recommendations and guidance for providing pharmaceutical care services during COVID-19 pandemic: a China perspective. Res Social Adm Pharm. 2020 (in press).

14. International Pharmaceutical Federation. Coronavirus 2019-nCoV Outbreak: information and interim guidelines for pharmacists and the pharmacy workforce. 2020; https://www.fip.org/file/4413. Accessed 15 April 2020.

15. Pharmacy Guild of Australia. COVID-19 Guide For Community Pharmacy. https://www.guild.org.au/resources/business-opera tions/COVID-19-Information/covid-19-guide-for-communitypharmacy. Accessed 20 March 2019.

16. Kosovo Pharmacists' Chamber. Komunikatë për shtyp nga Komiteti për Kordinimin dhe vlerësimin e situates epidemiologjike në bashkëpunim me Odën e FarmacistëvetëKosovës, dhe Agjencinë e Kosovës për Produkte dhe Pajisje Medicinale. http:// ofk-rks.net/category/lajme-dhe-aktivitete/. Accessed 20 March 2019.

17. American Society of Health-System Pharmacists. Coronavirus Disease 2019 (COVID-19) resource center. https://www.ashp. org/COVID-19. Accessed 20 March 2019.

18. Hanna LA, Hughes CM. Pharmacists' attitudes towards an evidence-based approach for over-the-counter medication. Int J Clin Pharm. 2012;34(1):63-71.

19. O’Neal KS, Crosby KM. Patients' perceptions of a pharmacistmanaged weight management clinic in a community setting. Res Social Adm Pharm. 2013;9(1):129-36.

20. Hoti K, Sunderland B, Hughes J, Parsons R. An evaluation of Australian pharmacist's attitudes on expanding their prescribing role. Pharm World Sci. 2010;32(5):610-21. 
21. Prochaska JO, Velicer WF. The transtheoretical model of health behavior change. Am J Health Promot. 1997;12:38-48.

22. Perepelkin J, Dobson RT. Influence of ownership type on role orientation, role affinity, and role conflict among community pharmacy managers and owners in Canada. Res Social Adm Pharm. 2010;6(4):280-92.

23. Graham C. NHS England advises pharmacies to prepare 'isolation space' for patients with suspected COVID-19. Pharm J. 2020.

24. Andalo D. Unprecedented demand' for OTC painkillers as COVID-19 outbreak spreads. Pharm J. 2020.

25. Wickware C. Competition watchdog to monitor price hikes during COVID-19 outbreak as pharmacists report rising cost of drugs. Pharm J. 2020.
26. Carico Jr. R, Sheppard J, Thomas CB. Community pharmacists and communication in the time of COVID-19: Applying the Health Belief Model. Res Social Adm Pharm. 2020 (in press).

27. Remuzzi A, Remuzzi G. COVID-19 and Italy: what next? Lancet. 2020. https://doi.org/10.1016/s0140-6736(20)30627-9 (in press).

Publisher's Note Springer Nature remains neutral with regard to jurisdictional claims in published maps and institutional affiliations. 